\title{
1 Bioactive milk lipids
}

2

3 Javier Fontecha*, Luis Miguel Rodriguez-Alcalá, María Visitación Calvo and Manuela Juárez

4 Institute of Food Science Research (CIAL; CSIC-UAM).

5 Department of bioactivity and Food analysis. Group of lipids.

6 Nicolás Cabrera, 9. Universidad Autónoma de Madrid (UAM) 28049 Madrid (Spain)

7

8 Abstract

9 Current information about the nutritional composition of milk fat is required for the consumer and therefore

10 essential for the successful development of dairy industries as well as marketing their products. The progress

11 in the knowledge concerning some milk fat components that possess biological properties and health benefits

12 beyond their nutritional significance, have a growing interest in the dairy industry to design and formulate 13 products that incorporate specific bioactive components derived from milk.

14 In the last two decades, special attention has been paid to the fatty acid (FA) composition on all short, 15 medium chain and branched fatty acid as well as linoleic conjugated acid (CLA) in milk and dairy products.

16 Trans monounsaturated fatty acids profiles from dairy fat has gained increasing relevance because may have 17 metabolic properties distinct from those of other origins, hydrogenation reaction for instance. Other minor 18 lipid compounds with biological activity, phospholipids and cholesterol are part of the fat globule membrane.

19 This review summarizes the current knowledge in milk fat research with a brief overview of the importance 20 of dairy lipids as biological molecules with emphasis in the different bioactive compounds present in this 21 fraction.

Keywords: Milk Fatty Acids, Conjugated Linoleic Acid, Trans Fatty Acids, Sphingolipids.

*Address correspondence to this author at the Group of Lipids, Department of Bioactivity and Food analysis. Institute of Food Science Research (CIAL; CSIC-UAM). 


\section{INTRODUCTION}

Lipids are one of the most important components of milk in terms of physical, organoleptic and nutritional properties they impart to dairy products. However, as result of their content in saturated fatty acids and cholesterol, nutritionists have advised against consumption of milk fat. Nevertheless in the last decade it have been reported the presence in milk fat of lipid compounds that exert important biological activities as butyric acid, conjugated linolenic acid (CLA), sphingolipids as constituents of the milk fat globule membrane and liposoluble vitamins. These compounds have commercial application in the development of functional foods to promote human health and diseases prevention. In order to enhance their activity and therefore the positive effects of its consumption many studies are focused to obtain natural enrichment dairy products as well as isolation of these compounds to be used as functional ingredients. A deeper knowledge on the regulation of the metabolic pathways of these bioactive lipids and their potential positive effect in human heath will be essential in the formulation of these products with added value.

In milk, lipids are present in the form of globules, with an average diameter of $3 \mu \mathrm{m}$ in sheep milk to $5 \mu \mathrm{m}$ in cow milk [1]. Fat globules contain a hydrophobic lipid core, consisting mainly of triglycerides (TAG), surrounded by a membrane mainly compose of phospholipids and glycoproteins. The structure and composition of the milk fat globule membrane (MFGM) is similar to all ruminant species and it represents approximately $1 \%$ of total milk fat volume [2]. Among the main health beneficial components of MFGM are cholesterolemia-lowering factor and anticarcinogenic agents [3] which allow considering MFGM as a potential nutraceutical. Furthermore milk lipids are carriers for important vitamins as A, D, E y K and carotenoids.

\section{TRIACYLGLYCERIDES (TAG)}

TAG constitutes the biggest group of milk fat lipids (nearly 98\%), including a large number of esterified fatty acids. TAG in milk fat present a wide range of molecular weights when distributed according to the number of carbon atoms (taking into account the sum of the carbon atoms of the three acyl radicals) from C26 to C54 [4]. Sheep and goat's milk have a higher percentage of medium-chain TAG (C26-C36) than cow's milk and a lower proportion of long chain TAG (C46-C54) [5]. Compared with TAG containing mainly long chain fatty acids those comprising saturated fatty acids with 6-10 carbons have lower melting points, smaller molecule size, and less energy dense. These chemical and physical properties affect their absorption and metabolism.

Given the great variance of fatty acids in milk fat, interest in the biological effects of the position occupied by individual fatty acids on the TAG molecule and the lipoprotein metabolism remains intense because may be relevant to their effects on CVD. The FA distribution in the TAG is species specific and nonrandom, with most of the $\mathrm{C} 4: 0$ and C6:0 esterified to the sn-3 position and the C16:0 occupies the sn-2 position. As the pancreatic lipase in the gut selectively hydrolyzes TAG at the sn-1 and sn-3 positions, short free fatty acids and 2-monoglycerides are produced. This unique position of C16:0 ensures that calcium in milk is highly absorbable.

\section{MILK FATTY ACID COMPOSITION}


Milk fat is a complex mixture of about 400 different fatty acids from 4 to 26 carbon atoms although only 30 of these compounds are in a concentration above $0.1 \%$ and the rest are present in trace amounts [6]. Saturated (SFA) or unsaturated (with one to four double bonds), are mostly of even number of carbon atoms but there is also odd-numbered moieties (2\%) as well as branched chain fatty acids. Milk from different species have characteristics fatty acid compositions: The content in short chain fatty acids: butyric (C4:0), caproic (C6:0), caprilic (C8:0) and capric (C10:0) acids are 2-3 fold higher in sheep than in goat's milk [7].

The five major acids from the quantitative point of view (C18:1, C16:0, C10:0, C14:0, and C18:0) account for more than $70 \%$ of the total fatty acids. The content of SFA in milk fat $(\sim 65 \%)$ has been associated with increments in the cardiovascular disease markers in plasma as LDL-cholesterol. On the other hand, only one third of SFA in milk, C12:0, C14:0 y C16:0 seems to be unhealthy when associated to an excessive consumption [8]. Recent studies have revealed that is more important to maintain a good balance among different fatty acids than the possible healthy or harmful effects they could exert individually $[9,10,11,12]$. Other studies concluded that those compounds considered as hypercholesterolemic may even have positive effects in moderate intake [13] and a recent meta-analysis of prospective epidemiologic studies [14] showed that there is no significant evidence for concluding that dietary saturated fat is associated with an increased risk of CHD or CVD.

Concerning to short chain fatty acids, beneficial effects of these compounds have been reviewed [15]. These authors reported the capacity of those fatty acids to reduce body weight and mainly body fat. They are particularly digestible, as they are hydrolysed preferentially from the TAG and transferred directly from the intestine to the portal circulation without resynthesis of TAG. Furthermore, these fatty acids are a preferred source of energy ( $\beta$-oxidation). Given in moderate amounts, in diets with not high fat supply, they may actually reduce fasting lipid levels more than oils rich in mono- or polyunsaturated fatty acids [16]. The butyric acid (C4:0) is present in milk fat in concentrations ranged 2-5\% and it has been described as an anticarcinogenic agent. At low concentrations butyric acid can inhibit growth in a wide range of human cancer cell lines [17] although it have been shown in animal studies that dietary fibers, which liberate a constant and elevated supply of butyrate to the colon, are most effective for prevention of chemically induced colon tumors. Furthermore, synergism between butyrate and other dietary components and common drugs in reducing cancer cell growth have also been shown [18]. On the other hand, the short and medium chain fatty acids (C4:0, C6:0, C8:0 and C10:0) can exert antimicrobial and antiviral activities both in vitro and in animal studies [19].

Stearic acid (C18:0) with an average concentration in milk fat of $11 \%$, is considered as neutral from the point of view of human health and can reduce plasma cholesterol as well as oleic acid (C18:1 cis 9, 15-23\% in milk fat). It is also interesting the presence of polyunsaturated fatty acids (PUFAs) as linoleic (18:2 cis 9 , cis 12) and linolenic acids (18:3 cis 9 , cis 12 , cis 15$)$ in amounts of 1-3\% respectively and recognized positive effect on cardiovascular health. Finally indicate that milk is the main source of conjugated linoleic acid (CLA) in the diet. It is known that the major CLA isomer (18:2 cis 9, trans 11) is a potent natural anticarcingenic agent [20].

Besides that, milk fat has other fatty acids as the branched chain fatty acids as 13-methyl tetradecanoic acid (iso-15:0), phytanic acid (3, 7, 11, 15-tetra methyl-16:0), and the derivative of the latter, pristanic acid, which are known to bind to nuclear receptors, with subsequent modification of gene expression. Others as phytanic 

(C16:1 cis 9), has been demonstrated to effect a hormone-like (lipokine) activation of glucose uptake in muscle cells [22]. Among milk fats, these FA are found in higher concentrations in goat's milk and are relevant as contributors to the milk fat melting point and also useful in clinic studies as human intake markers of milk fat while they are no present in other animal fats [23].

According to this, in the last years, studies have been accomplished resulting in high number of scientific publications with the aim to reconsider the significant activity of fatty acids present in milk fat and their effects on human health $[9,24,25,26,27,11,12]$.

\section{III.1 CONJUGATED LINOLEIC ACID (CLA)}

The generic name CLA is a collective term embracing all positional and geometric isomers of linoleic acid, which contain a conjugated double bond system. Data from in vitro studies and animal models have been used to suggest that the isomer C18:2 cis 9, trans 11 (known as rumenic acid, RA) is responsible for CLA anticarcinogenic and antiatherogenic properties, as well as a multiplicity of potentially beneficial effects on human health [28, 9, 29, 30, 31, 32]. trans 11 (vaccenic acid, VA), its physiological precursor [33]. In the first studies concerning the total CLA mean content was described the following order: sheep> cow > goat milk fat, 1.2; 0.7 and $0.6 \%$ of total fatty acids, respectively [34]. RA is the most abundant isomer and accounts for around $75 \%$ of the total CLA. From initial studies showing their anticarcinogenic affects as inhibited epithelial tumors in animals [35], a high number of research works have been performed in the determination of their biological and physiological properties [20]. The available information on the effects of CLA in cancer cell metabolism together with their antiproliferative and apoptotic activities [36] place CLA as an interesting compound in cancer therapy. Even more, recent studies reported that high CLA intake through high fat content dairy products may reduce the risk of colon-rectal cancer [37].

There are many possible metabolic pathways involved in the anticancer activity of CLA. It has been suggested that CLA competes with arachidonic acid (C20:4) in the cyclooxygenase reaction then reducing the concentration of prostaglandins and thromboxane of the 2-series [38]. CLA can suppress cyclooxygenase gene expression and reduce the release of pro-inflammatory cytokines such as TNF-alpha and interleukin in animals [38] as well as also seem to activate the PPARs transcription factors, reduce the initial step in the activation of NF-kappa B thereby reducing cytokines, adhesion molecules and other induced by stress [39]. As mentioned, besides RA, other CLA isomers have been associated with several metabolic processes related to health. Thus the C18:2 trans 10, cis 12, has achieved a great relevance since it have been reported to promote weight loss [40,9] although it could cause decrease in glucose levels and plasma insulin resistance [41,42]. RA was tested in breast cancer cell cultures and concluded to act as a human estrogen blocking agent while C18:2 trans 9, trans 11 inhibits growing of colon cancer cells [43].

Studies in humans are scarce but in the last years some clinical trials have been carried out using CLA isomers mixtures. Thus, Tricon et al., [44] had showed that incorporation of RA and C18:2 trans 10, cis 12 into the diet of healthy volunteers affects positively to plasma lipid levels leading to a significant reduction of 
10, cis 12 appears not to be as beneficial to the CVD risk markers. Recent studies in obese and overweight children (6-10 yr old) consuming a CLA enriched chocolate milk, found attenuation in the BMI increment but did not improve plasma lipids or glucose and decreased HDL cholesterol level [45].

About the other CLA isomers, the C18:2 cis 9 cis 11 has been shown to be also a blocking agent of estrogen signaling in human breast cancer cells in vitro assays [46]. Other studies have reported the potent inhibitory effect of C18:2 trans 9 trans 11 on the growth of human colon cancer cells [47] as well as antiproliferative and pro-apoptotic effects on bovine endothelial cells [48]. However, further research is needed in this field.

\section{III.2 TRANS FATTY ACIDS (TFA)}

TFA content in milk fat ranged from 2.5 to $5 \%$ of total fatty acids, depending on diet and season. Monoene TFAs are the main compounds in all species. In ruminant, sheep's milk presented the highest quantities, after cows and lately goats milk fat. The pattern of C18:1 trans isomer distribution is however qualitatively identical in the three species [49]. TFA in dairy fat are not seen as bioactive lipids in a positive sense. But since TFA have come under scrutiny due to their influence on lipid levels and on other risk factors for CVD, the question whether all TFA are alike or whether TFA isomers from dairy fat may have metabolic properties distinct from those of other origins, hydrogenation reaction for instance, has gained increasing relevance [50].

The main source of TFA consumed daily by humans is partially hydrogenated vegetable fats and oils, although these compounds also occur naturally in ruminant milk result of partial biohydrogenation of PUFA caused by rumen microorganisms. There is a considerable overlap of TFA isomers in fats of ruminant origin and partially hydrogenated vegetable oils, with many isomers in common. However the isomer profile of hydrogenated vegetable fats is very different. During the hydrogenation of vegetable fats a wide range of trans monounsaturated fatty acids are principally formed (e.g. C18:1 trans 9, elaidic acid) while the main TFA in milk fat is C18:1 trans 11, VA [24]. The importance of VA lies in its already cited role as a precursor of the main isomer of CLA, rumenic acid (RA) physiologically the most relevant bioactive compound present in milk fat. This synthesis not only occurs in the bovine mammary gland [51,52] but also in human and other animal tissues [53, 54, 55]. The rate of VA to total monoene TFA in milk fat is around 40-60\% [56,49,57], whereas elaidic acid is only present in considerably smaller amounts (average of 5\% of the total TFA). In contrast, the majority of hydrogenated vegetable oils have a TFA profile with a gauss distribution showing high concentrations of $\mathrm{C} 18: 1$ trans 9 and trans 10 .

Individual TFA isomers could have differing physiological effects [58]. There is evidence of unfavorable effects of TFA from hydrogenated vegetable oils on LDL and other risk factors of atherosclerosis whereas, the predominant TFA in milk, VA, would not exert these detrimental effects [24,18]. Most of the studies reported that the positive association with the risk of CVD could be explained entirely by the intake of TFA from hydrogenated vegetable oils. Pfeuffer and Scherezenmeir [59] also compiled works addressing the effect of TFA intake on CVD. Several of the large prospective studies, which established the notion the intake of TFA increases CVD risk, showed a significant inverse association with intake of animal or dairy TFA, a non-significant inverse trend or at least no change with increasing intake of TFA from such sources [59]. Recent studies suggest that 
TFA from animal sources did not lead to higher cardiovascular risk [60,61]. Also Tricon et al., [62] and Wanders et al., [63] found that increments in the concentrations of TVA and RA are not related to CVD

\section{MINOR LIPID COMPOUNDS}

Milk presents complex lipids as phospholipids and different liposoluble compounds (sterols, $\beta$-carotene and vitamins) with biological activity.

Phospholipids are associated with the milk fat globule membrane (MFGM) and account for $0.5-1 \%$ of total milk lipids [64, 65]. Sphingolipids and their active metabolites, ceramides and sphingosines, were determined as effective bactericidal agents on pathogens and they are reported to have tumor-suppressing properties by influencing cell proliferation and are highly bioactive compounds with bacteriostatic and cholesterollowering properties $[9,18,66]$. Further, some phospholipids exhibit antioxidative properties in dairy fat products with low water content [67]. However, to date, only very limited data are available on the phospholipids content in dairy products and the influence of processing and environmental variables on its concentration and relative distribution. The phospholipids proportions in the different ruminant milks are similar: Phosphatidylcholine (35\%) phosphatidyl-ethanolamine (30\%), and sphingomyelin $(25 \%)$ are the major, with smaller amounts of phosphatidylinositol (5\%) and phosphatidylserine (3\%), [7].

Other molecules as ether lipids (alkyldiacylglycerols and alkylacylphospholipids) are present in milk lipid fraction at low amounts but have been also claimed as bioactive components [67]. These compounds are incorporated and accumulated in cell membranes and thereby influence biochemical and biophysical processes [18].

The sterol fraction of milk fat and especially the cholesterol is of nutritional interest because high levels of cholesterol in plasma are associated with an increasing risk of CVD. Nevertheless today is well known trough analysis of the available epidemiological and clinical data that for the general population, dietary cholesterol makes no significant contribution to atherosclerosis and risk of CVD [68].

Cholesterol (about 260-270 mg /100 g fat) is also important for the resorption of fats and its role as precursor in the synthesis of steroid hormones. Small amounts of other sterols implicated in cholesterol biosynthesis have also been found in milk fat: lanosterol, dihydrolanosterol, desmosterol, and lathosterol.

\section{FINAL REMARKS}

The public perception of whole milk fat dairy products is a significant challenge that faces the dairy industry because of their perceived negative effects on human health. Besides, the current nutritional recommendations for these dairy products are that their consumption should be limited. However, milk is a complex food with a host of nutrients, and the conclusions from long-term studies and meta-analyses suggest a reduction in risk in the subjects with the highest dairy consumption relative to those with the lowest intake for almost all-cause deaths and diseases.

The diversity of milk fat lipids, the variety of bioactive substances that it contains and their physiological functions remains poorly understood. Therefore, further research is required to establish the contribution of these bioactive components of milk fat in human health. 
[1] Park YW, Juárez M, Ramos M, Haenlein GFW. Physico-chemical characteristics of goat and sheep milk. Small Rumin. Res. 2007; 68, 88-113.

[2] Lercker, G, Cocchi, M. The milk fat: membranes, composition and structure. Prog Nutr 2010, 12: 183-194.

[3] Spitsberg, VL. Bovine milk fat globule membrane as a potential neutraceutical. J Dairy Sci 2005; 88: 2289-2294.

[4] Fontecha, J, Goudjil H, Ríos JJ, Fraga MJ, Juárez, M. Identity of the major triacylglycerols in ovine milk fat. Int Dairy J 2005; 15:1217-1224.

[5] Goudjil, H., Fontecha, J., Fraga, M.J., and Juárez, M. TAG composition of ewe's milk fat. Detection of foreign fats. J Am Oil Chem Soc 2003; 80: 219-222.

[6] Jensen R.G. (2002). The composition of bovine milk lipids. Journal of Dairy Science. 85:295-350.

[7] McGibbon and Taylor. In: Advanced Dairy Chemistry, Vol. 2, Lipids, $3^{\mathrm{a}}$ Ed, Fox, P.F. y McSweeney Eds, Springer: New York 2006; pp.1-42.

[8] Legrand, P. Intérêt nutritionnel des principaux acids gras des lipides laitiers. Sci. Aliments 2008; 28:34-43

[9] Parodi, PW. Milk fat in human nutrition. Aust. J. Dairy Technol. 2004; 59: 3-59.

[10] Shingfield KJ., Chilliard Y, Toivonen V, Kairenius P, Givens DI. Trans fatty acids and bioactive lipids in ruminant milk. Adv. Exp. Med. Biol. 2008; 606:3-65.

[11] Steijns, JM. Dairy products and health: Focus on their constituents or on the matrix. Int. Dairy J. 2008; 18: 425-435.

[12] Lecerf, J.M. (2008). Acides gras et maladies cardiovasculaires. Sci. Aliments. 28:53-67.

[13] Dabadie H, Peuchant E, Bernard M, Leruyet P, Mendy F. Moderate intake of myristic acid in sn-2 position has beneficial lipidic effects and enhances DHA of cholesteryl esters in an interventional study. J. Nutr. Biochem.2005; 16:375-382.

[14] Siri-Tarino PW, Sun Q, Hu FB, Krauss MN. Saturated fat, carbohydrate, and cardiovascular disease. Am. J. Clin. Nutr. 2010; 91:535-546.

[15] Maier S, Reich E, Martin R, Bachem M, Altug V, Hautman RE, Gschwend JE. (2000) Tributyrin induces differentiation, growth arrest and apoptosis in androgen-sensitive and androgen-resistant human prostate cancer cell lines. Int. J. Cancer. 2000; 88: 245-251.

[16] Marten B, Pfeuffer M, Schrezenmeir J. (2006). Medium-chain triglycerides. Int Dairy J 2006; 16(11), 1374-1382.

[17] Blank-Porat D, Gruss-Fischer T, Tarasenko N, Malik Z, Nudelman A, Rephaeli A. The anticancer prodrugs of butyric acid AN-7 and AN-9, possess antiangiogenic properties. Cancer Letters, 2007; 256(1): p. 39-48.

[18] Parodi PW. Nutritional significance of milk lipids. Advanced Dairy Chemistry, Volumen 2:. Lipids, $3^{a}$ edición. Editores: P.F. Fox y P.L.H. McSweeney, Springer, EEUU 2006; pp. 601-639

[19] Neyts, K., Huys, G., Uyttendaele, M., Swings, J., Debevere J. (2000). Incidence and identification of mesophilic Aeromonas spp. from retail foods. Lett. Appl. Microbiol. 2000; 31: 359-363.

[20] Parodi, P.W. (2008). Milk lipids: their role as potential anti-cancer agents, Sci. Aliments. 28:44-52.

[21] Hallgren B, Niklasson A, Stallberg G, Thorin H. On the occurrence of 1-O(2methoxyalkyl)glycerols in human colostrums, human milk, cow's milk, sheep's milk, human red bone marrow, red cells, blood plasma and uterine carcinoma. Acta Chem. Scand. 1974; B28:1029-1034.

[22] Olefsky, J. M. Fat Talks, Liver and Muscle Listen. Cell 2008; 134(6): 914-916.

[23] Vlaeminck B, Fievez V, Cabrita ARJ, Fonseca AJM, Dewhurst RJ. (2006). Factors affecting oddand branched-chain fatty acids in milk: A review. Anim. Feed Sci. Technol. 2006; 131: 389-417.

[24] IDF-International Dairy Federation. Trans fatty acid: Scientific Progress and labelling. Bulletin of International Dairy Federation 2005; 393. Brusseles. Belgium.

[25] German JB, Dillard CJ. Composition, Structure and Absorption of Milk Lipids: A Source of Energy, Fat-Soluble Nutrients and Bioactive Molecules. Crit. Rev. Food Sci. Nutr. 2006. 46(1): 57-92.

[26] Akaln S, Gönç S, Ünal G. Functional Properties of Bioactive Components of Milk Fat in Metabolism. Pak. J. Nutr. 2006; 5: 194-197.

[27] IDF-International Dairy Federation (2007) The health benefits of milk and dairy products. Bulletin International Dairy Federation2007; 417. Brusseles. Belgium.

[28] Ip MM, Masso-Welch PA, Ip, C. Prevention of mammary cancer with conjugated linoleic acid: role of stroma and the epithelium. J Mammary Gland Biol Neoplasia 2003; 8: 103-108. 
[29] Lee KW, Lee HJ, Cho HY, Kim YJ. Role of the conjugated linoleic acid in the prevention of cancer. Crit. Rev. Food Sci. Nutr. 2005; 45:135-144.

[30] Battacharaya A, Banu, J, Rahman M, Causey J, Fernandes G. Biological effects of conjugated linoleic acids in health and disease. J Nut Biochem 2006; 17: 789-810.

[31] Yurawecz MP, Roach JAG, Sehat N, Mossoba MM, Kramer JKG, Fritsche J, Steinhart H, Ku Y. A New Conjugated Linoleic Acid Isomer, 7 trans, 9 cis-Octadecadienoic Acid, in Cow Milk, Cheese, Beef and Human Milk and Adipose Tissue. Lipids 1998; 33: 803-809.

[32] Larsson SC, Bergkvis L, Wolk A. Conjugated linoleic acid intake and breast cancer risk in a prospective cohort of Swedish women. Am. J. Clin. Nutr. 2009; 90:556-560.

[33] Luna, P, Fontecha J, Juárez M, de la Fuente MA. Effects of a Diet Supplemented with Linseed on the CLA Content in Ewes Milk Fat. Lipids 2005; 40: 445-454.

[34] Jahreis G, Fritsche J, Kraft J. Species dependent, seasonal, and dietary variation of conjugated linoleic acid in milk. In: Advances in Conjugated Linoleic Acid, Volume 1, Yurawecz MP, Mossoba MM, Kramer JKG, Pariza MW, Nelson GJ. Eds., AOCS Press: Champaign Il, 1999; pp. 215-225.

[35] Ha YL, Grimm NK, Pariza MW. Anticarcinogens from fried ground beef: heat altered derivatives of linoleic acid. Carcinogenesis 1987; 8: 1881-1887.

[36] Ochoa JJ, Farquharson AJ, Grant I, Moffat LE, Heys SD, Wahle KW. Conjugated linoleic acids (CLAs) decrease prostate cancer cell proliferation: different molecular mechanisms for cis-9, trans11 and trans-10, cis-12 isomers. Carcinogenesis 2004; 25:1185-91.

[37] Larsson SC, Bergkvist L, Wolk A. High-fat dairy food and conjugated linoleic acid intakes in relation to colorectal cancer incidence in the Swedish Mammography Cohort. Am. J. Clin. Nutr. 2005; 82:894-900.

[38] Akahoshi A, Koba K, Ichinose F, Kaneko M, Shimoda A, Nonaka K, Yamasaki M, Iwata T, Yamauchi Y, Tsutsumi K, Sugano M. Dietary protein modulates the effect of CLA on lipid metabolism in rats. Lipids 2004; 39:25-30.

[39] Cheng WL, Lii CK, Chen HW, Lin TH, Liu KL. Contribution of conjugated linoleic acid to the suppression of inflammatory responses through the regulation of the NF-kappaB pathway. J. Agric. Food Chem. 2004; 52:71-8.

[40] Belury MA. Dietary conjugated linoleic acid in health: physiological effects and mechanisms of action. Ann Reviews Nut 2002; 22: 505-531.

[41] Riserus U, Brismar K, Arner P, Vessby B. Treatment with dietary trans- 10 cis- 12 conjugated linoleic acid causes isomer-specific insulin resistance in obese men with the metabolic syndrome. Diabetes Care 2002; 25:1516-1521.

[42] Khanal RC, Dhiman TR. Biosynthesis of conjugated linoleic acid (CLA): A review. Pak. J. Nutr. 2004; 3:72-81.

[43] Coakley M, Johnson MC, McGrath E, Rahman S, Ross RP, Fitzgerald GF, Devery R, Stanton C. Intestinal Bifidobacteria That Produce trans-9, trans-11 Conjugated Linoleic Acid: A Fatty Acid With Antiproliferative Activity Against Human Colon SW480 and HT-29 Cancer Cells. Nut Cancer 2006; 56: 95 - 102.

[44] Tricon S, Burdge GC, Kew S, Banerjee T, Russell JJ, Jones EL, Grimble RF, Williams CM, Yaqoob $\mathrm{P}$, Calder PC. Opposing effects of cis-9, trans-11 and trans-10, cis-12 conjugated linoleic acid on blood lipids in healthy humans. Am. J. Clin. Nutr. 2004; 80:614-20.

[45] Racine, N.M., Watras, A.C., Carrel, A.L., Allen, D.B., McVean. J.J., Clark, R.R., O'Brien, A.R., O'Shea, M., Scott, C.E., Schoeller, D.A. Effect of conjugated linoleic acid on body fat accretion in overweight or obese children. Am. J. Clin. Nutr. 2010; 91: 1157-64.

[46] Tanmahasamut P, Liu J, Hendry LB, Sidell N. (2004). Conjugated Linoleic Acid Blocks Estrogen Signaling in Human Breast Cancer Cells. J Nut. 2004; 134(3), 674-680.

[47] Beppu F, Hosokawa M, Tanaka L, Kohno H, Tanaka T, Miyashita K. Potent inhibitory effect of trans9, trans11 isomer of conjugated linoleic acid on the growth of human colon cancer cells. J. Nutr. Biochem. 2006; 17(12): 830-836.

[48] Lai, KL, Torres-Duarte A, Vanderhoek J. 9-trans,11-trans-CLA: Antiproliferative and proapoptotic effects on bovine endothelial cells Lipids 2005; 40(11): 1107-1116.

[49] Precht D, Molkentin J, Destaillats F, Wolf RL. (2001). Comparative studies on individual isomeris 18:1 acids in cow, goat and ewe milk fat by low-temperature high-resolution capillary gas-liquid chromatography. Lipids 2001; 36:827-832.

[50] Glew RH, Chuang LT, Berry T, Okolie H, Crossey MJ, VanderJagt DJ. Lipid Profiles and trans Fatty Acids in Serum Phospholipids of Semi-nomadic Fulani in Northern Nigeria. J Health Popul Nutr 2010; 28: 159-166 
[51] Griinari JM, Bauman DE. Biosynthesis of conjugated linoleic acid and its incorporation into meat and milk in ruminants In: Advances in CLA Research, Volume 1 Yurawecz, M.P., Mossoba, M.M., Kramer, J.K.G., Pariza, M.W., and Nelson, G.J. Eds, AOCS Press: Champaign, IL, 1999; pp. 180200.

[52] Field CJ, Blewett, HH, Proctor S, Vine D. Human health benefits of vaccenic acid. Appl. Physiol. Nutr. Metab. 2009; 34: 979-991.

[53] Turpeinen, A.M., Mutanen, M., Aro, A., Salminen, I., Basu, S., Palmquist, D.L., Griinari J.M. (2002). Bioconversion of vaccenic acid to conjugated linoleic acid in humans. American Journal Clinical Nutrition. 76:504-10.

[54] Mosley EE, McGuire MK, Williams JE, McGuire MA. Cis-9, Trans-11 conjugated linoleic acid is synthesized from vaccenic acid in lactating women. J Nut. 2006; 136:2297-2301.

[55] Kuhnt K, Kraft J, Moeckel P, Jahreis G. Trans-11-18:1 is effectively delta9-desaturated compared with trans-1218:1 in humans. Br. J. Nutr. 2006; 95:752-761.

[56] Wolff RL. Content and distribution of trans-18:1 acids in ruminant milk and meat fats. Their importance in European diets and their effect on human milk. J. Am. Oil Chem. Soc. 1995; 72:259272.

[57] Goudjil, H., Fontecha, J., Luna, P., De la Fuente, M.A., Alonso, L., and Juárez, M. (2004). Quantitative characterization of unsaturated and trans fatty acids in ewe's milk fat. Le Lait 2004; 84:473-482.

[58] Anadón A, Martínez-Larrañaga MR, Martínez MA, Ares I, Ramos E, Gómez-Cortés P, Juárez M, De la Fuente MA. Acute oral safety study of dairy fat rich in trans-10 C18:1 versus vaccenic plus conjugated linoleic acid in rats. Food Chem. Toxicol. 2010; 48:591-598.

[59] Pfeuffer M, Schrezenmeir J. Impact of trans fatty acids of ruminant origin compared with those from partially hydrogenated vegetable oils on CHD risk. Int. Dairy J. 2006; 16:1383-1388.

[60] Willett, W.C. (2006). Trans fatty acids and cardiovascular disease - epidemiological data. Atherosclerosis 2006; 7:5-8.

[61] Willett WC, Mozaffarian D. Ruminant or industrial sources of trans fatty acids: public health issue or food label skirmish?. Am. J. Clin. Nutr. 2008; 87:515-516.

[62] Tricon S, Burdge GC, Jones EL, Russell JJ, El-Khazen S, Moretti E. Effects of dairy products naturally enriched with cis-9,trans-11 conjugated linoleic acid on the blood lipid profile in healthy middle-aged men. Am. J. Clin. Nutr. 2006; 83: 744-753.

[63] Wanders AJ, Leder L, Banga JD, Katan MB, Brouwer IA. A high intake of conjugated linoleic acid does not affect liver and kidney function tests in healthy human subjects. Food Chem. Toxicol. 2010; 48: 587-590.

[64] Rombaut R, Dewettinck K. Properties, analysis and purification of milk polar lipids. Int. Dairy J. 2006; 16:1362-1373.

[65] Rodríguez-Alcalá LM, Fontecha J. Major lipid classes separation of buttermilk, and cows, goats and ewes milk by high performance liquid chromatography with an evaporative light scattering detector focused on the phospholipid fraction. J Chrom A 2010. 1217: 3063-3066.

[66] Gustavsson M, Hodgkinson SC, Fong B, Norris C, Guan JA, Krageloh CU, Breier BH, Davison M, McJarrow P, Vickers MH. Maternal supplementation with a complex milk lipid mixture during pregnancy and lactation alters neonatal brain lipid composition but lacks effect on cognitive function in rats. Nutr. Res. 2010;30: 279-289.

[67] Molkentin J. Occurrence and biochemical characteristics of natural bioactive substances in bovine milk lipids. Br. J. Nutr.2000; 84:47-53.

[68] McNamara DJ. Dietary cholesterol and atherosclerosis. Biochim. et Biophys. Acta. 2000; 1529: 310-320. 